Path. Microbiol. 1961;24:219

\title{
Zum 80. Geburtstag von Prof. Dr. med. Hugo Braun
}

Am 7. April dieses Jahres beging Prof. Dr. med. Hugo Braun, Direktor des Ludolph-BrauerInstituts - der früheren deutschen Forschungsanstalt für Tuberkulose - in voller Rüstigkeit seinen 80. Geburtstag. Braun promovierte 1906 an der deutschen Uni-versität in Prag, habilitierte sich 1916 unter Max Neisser in Frankfurt a. M., wo er 1921 als Nachfolger von Hans Sachs zum a. o. Professor ernannt wurde. In dieser Zeit hatte er, seiner Zeit weit vorauseilend, das Arbeitsgebiet gefunden, das ihn zeitlebens be-schäftigen sollte, und für das ihm 1931 der PaulEhrlich-Preis und 1960 die Robert-Koch-Medaille verliehen wurde.

Kommendes ahnend folgte er 1933 einem Ruf auf den Lehr-stuhl für Hygiene und Mikrobiologie in Istanbul, von wo aus er einer der ersten ausländischen Mitarbeiter unserer 1938 gegrün-deten Zeitschrift wurde. Diese Berufung hatte ihn nicht nur vor dem Schlimmsten bewahrt, sondern ihm auch die Arbeitsmöglich-keit erhalten. Den Dank erstattete er den türkischen Behörden durch die Ausbildung zahlreicher Schüler, die heute in Amt und WÜГden stehen und ihm in Freundschaft verbunden blieben.

1949 erfolgte seine Rückberufung auf den Lehrstuhl nach München, womit - obwohl er dort nur Institutstrümmer antraf - sein Lebenswunsch in Erfüllung ging. 1951 übernahm er zu-sätzlich die Leitung der Deutschen Forschungsanstalt für Tuberkulose, die er nach seiner 1958 erfolgten Emeritierung beibehielt und in deren Laboratorien er sich auch heute noch wohl fühlt. Mehr als 200 Arbeiten sind von ihm allein oder von ihm und seinen Schülern gezeichnet, und eine große Zahl weiterer Publi-kationen waren von ihm inspiriert.

Wer immer das Glück hatte, mit Hugo Braun zusammenzu-treffen, wird sich stets der mit vornehmer Klugheit geführten Unterhaltung und des trotz aller Ehrungen bescheiden gebliebenen Forschers und Menschen mit Vergnügen erinnern. Mögen ihm noch lange fruchtbare und ihn selbst beglückende Jahre vergönnt sein

A. Grumbach, Zurich. 